\title{
A NEW SPECIES OF MYRMECOPHILOUS COCCINELLIDAE, WITH NOTES ON OTHER HYPERASPINI (COLEOPTERA)*
}

\author{
By Edward A. Chapin \\ Museum of Comparative Zoology, Harvard University
}

During the past few years, Professor Daniel H. Janzen of the Department of Entomology of Kansas University has worked during the summers in Mexico and Central America on a project dealing with the relation of ants of the genus Pseudomyrmex to species of the thorn-bearing plants of the genus Acacia. In the course of the work larvae and pupae of a coccinellid were found inhabiting some of the hollowed spines abandoned by the ants. Two adult beetles were reared and sent to me for study. These proved to be the same species as two specimens collected in Mexico by Mr. N. L. H. Krauss which had been set aside as undescribed in my collection. As the species is so unlike in form from other hyperaspines known to me, the genus was not immediately recognizable. After dissection and preparation of the necessary slides, the species was found to be nearest to Hyperaspis and has been so assigned here. Hyperaspis is certainly composite as it now stands in the Korschefsky catalog and merits serious study by one who has adequate material at his disposal.

Myrmecophiles of the tribe Hyperaspini are already known from both hemispheres. J. B. Smith ( 1886) reported the presence of larvae of Brachyacantha ursina (Fabricius) in ants' nests and E. A. Schwarz (I890) reported that same species as abundant near Washington, D. C. in colonies of Lasius claviger Roger. F. Silvestri (1903) found Hyperaspis reppensis (Herbst) in the vicinity of Napoli, Italy in the nests of Tapinoma erraticum nigerrimum $\mathrm{Ny}$ lander. W. M. Wheeler (I9II) summed up what was known of myrmecophilous Coccinellidae and recorded the finding of Brachyacantha quadripunctata (Melsh.) from the nests of Lasius umbratus var. aphidicola Walsh at Great Blue Hill, Massachusetts. It is quite possible that the B. ursina of Smith and Schwarz is actually B. quadripunctata.

The genera composing the tribe Hyperaspini, as listed in the JunkKorschefsky catalog I93I, fall into one or the other of two divisions which are based on the structure of the male and female genitalia. The first division within the tribe is composed of the genera Brachya-

\footnotetext{
*Published with the aid of a grant from the Museum of Comparative Zoology.

Manuscript received by the editor November 16, 1966.
} 

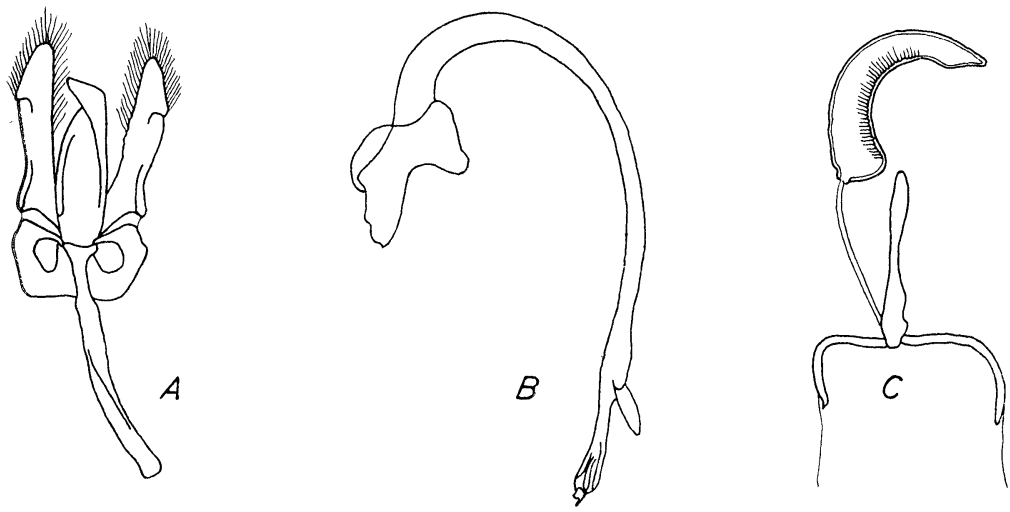

Figure 1. Brachyacantha dentipes (Fabricius). A. Aedeagus (without sipho) ; B. Sipho; C. Femals genitalia, showing receptaculum seminis, sperm duct, infundibulum, and apex of bursa.

cantha Chevrolat, Cyra Mulsant, Hinda Mulsant, and probably Cleothera Mulsant. 'These genera are characterized in the males by parameres attached to the tegmen in the normal manner for Coccinellidae, that is, attached to the basal ring at the base of the median lobe and without special "roots" which pass through or almost through the ring; in the females by the presence of a complicated infundibular structure and by the possession of a normally formed, more or less sausage-shaped, receptaculum seminis. 'The infundibulum in these genera consists of three or four arms, two or three of which lie in the wall of the bursa copulatrix and act as supporting struts. The remaining arm stands free, and the sperm duct joins the bursa at the junction of these arms. The sperm duct is relatively short. "The receptaculum lacks well-developed nodulus or ramus. These genera also agree in having eleven-segmented antennae and toothed tarsal claws.

Iyperaspis Redtenbacher, IIyperaspidius Crotch, Itelesius Casey, Thalassa Mulsant, Corystes Mulsant, and Oxynychus Leconte and probably Diazonema Weise, Tiphysa Mulsant, and Menoscelis Mulsant, are included in the second division. These genera are characterized in the males by parameres which appear to be outgrowths of sclerotized but unpigmented structures or "roots," within or extending beyond the basal ring; in the females by the possession of a compound receptaculum seminis, and by the absence of an infundibulum. Among these genera one finds species with nine, ten, or eleven antennal segments and with toothed or toothless claws. 
The key which follows is limited to those genera which I have been able to study in detail and serves only to give some indication of the relationships existing between those genera.

\section{Key to Certain genera of Hyperaspini}

I. Parameres attached in the usual manner to the tegmen; infundibulum present; receptaculum seminis simple; antenna elevensegmented

2

Parameres attached to root-like structures within basal ring; infundibulum absent; receptaculum compound; antenna nine, ten, or eleven-segmented

2. Infundibulum with three arms; anterior tibia with a sharp tooth; median lobe of aedeagus asymmetrical

Infundibulum with four arms, the fourth arm a dorsal supporting strut in wall of bursa

3. Anterior tibia slender, not armed; median lobe asymmetrical

Cyra

Anterior tibia with expanded outer margin, which is finely and regularly serrulate; median lobe symmetrical, in form of a slender isosceles triangle; parameres modified at apices .. Hinda

4. Antenna eleven-segmented ............................................... 5

Antenna with less than eleven segments …………................. 7

5. Anterior tibia slender, without denticles .... Hyperaspis (part) Anterior tibia with outer edge broadly rounded ….................... 6

6. Tarsal claw with basal tooth ................................... Thalassa

Tarsal claw simple ................................................... Helesius

7. Antenna ten-segmented ................................................... 8

Antenna nine-segmented; anterior tibia broadly rounded

Corystes

8. Tibia simple; tarsal claw with basal tooth .... Hyperaspis (type)

Tibia simple; tarsal claw without tooth ............... Hyperaspidius

\section{Hyperaspis acanthicola, n. sp.}

Male: Length - $13 \mathrm{~mm}$. Form subcylindrical, the side margins nearly parallel from humeri to level of apex of elytral suture (Fig. 2A). Color piceous black, heavily marked above with whitishyellow; beneath, the lateral portions of the prosternum and abdominal sternites, the mesepisterna, and legs, reddish-yellow. Head entirely pale, pronotum with anterior half pale, posterior half dark, the dark area strongly bilobed on disc. Each elytron has the familiar pattern of five pale spots (2.2.I) on piceous black, so commonly found among 

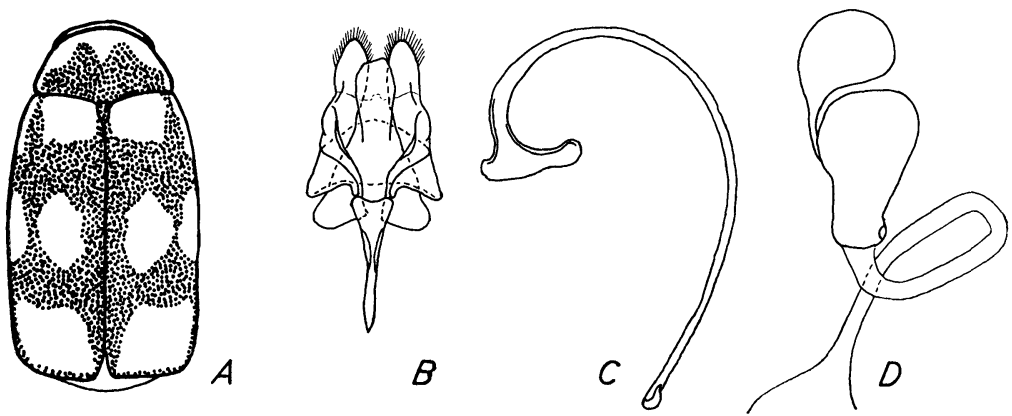

Figure 2. Hyperaspis acanthicola new species. A. Entire insect, dorsal view; B. Aedeagus (without sipho); C. Sipho; D. Female genitalia, showing compound receptaculum seminis, sperm duct, and apex of bursa.

the species of Brachyacantha, Cyra, and to a lesser extent, Hyperaspis. The scutellar spot is transverse, of irregular shape; it extends along the basal margin of the elytron from the scutellum to the base of the humeral callus, and is approximately one and one-half times wider than long. The humeral spot lies almost entirely on the nearly vertical flank of the elytron, is nearly rectangular and about twice as long as wide; it touches both basal and lateral margins of the elytron and extends backward slightly farther than the scutellar spot. The third and fourth spots, situated slightly postmedian, are almost connected. The outer and larger of the two extends from the lateral margin to the middle line of the elytron, is wider than long and remotely suggests a distorted hexagon. The inner spot is longer than wide, somewhat lozenge-shaped, and is well separated from the suture. The fifth and largest spot lies close to but does not touch the apical and lateral margins of the elytron and approaches the sutural margin only at its apex.

The head is finely and densely punctate on a finely alutaceous surface. Surface of the pronotum is similar to that of the head but the punctation is more sparse. Surface of the elytra is shining, slightly uneven, the punctation similar to that of the pronotum. Metasternum highly polished, virtually impunctate in median area, abdominal sternites and flanks of the metasternum noticeably more coarsely punctate than other parts of the body. The femora, especially those of legs III, somewhat inflated. Elytral epipleura narrow, ending just behind the level of legs III, without well-defined cavities for the reception of the femoral apices. Abdomen with six visible stern- 
ites, the sixth short and very broad, the corresponding tergite only half its breadth. The sternites without sexual modifications.

Genitalia (Fig. 2B, C). In general appearance most nearly resemble those of $H$. reppensis (Hbst.). The median lobe is slightly longer than wide and is almost symmetrical. The free portion of a paramere is one-sixth longer than the median lobe but only half as long as the portion enclosed within the basal ring which is twisted through an arc of $180^{\circ}$ and which protrudes beyond the basal ring and appears to provide a surface for muscle attachment. The sipho is normal in form, slightly modified at apex.

Female: Length $3 . \mathrm{I}-3.4 \mathrm{~mm}$. Form and punctation essentially as in male. Head dark beneath and with a transverse dark stripe on vertex. Pronotum largely dark, the extreme anterior margin and the anterior angles pale. Prosternum dark, propleura, mesepipleura, elytral epipleura and lateral margins of abdominal sternites pale.

Genitalia (Fig. 2D). Hemisternites broad and rounded, styli very small but with relatively long and conspicuous setae. Bursa copulatrix broad at base, rapidly tapering to meet the sperm duct of large diameter. Infundibulum absent. Receptaculum seminis is compound; the basal portion, which corresponds to the nodulus, ramus, and lower part of cornu, is pear-shaped and of moderately firm texture. There is no appendix at its apex, as in most of the species of Iyperaspis. Accessory gland pore located adjacent to the attachment of the sperm duct. The apical portion, which appears to correspond to the apical portion of cornu, is retort-shaped and is joined to the basal portion at about the middle of its length.

Holotype - a male, head appendages, legs, genitalia and abdominal sternites on slide, from Veracruz, Ver., México, May i956, N. L. H. Krauss, (U. S. N. M. no. 6933 I ). Paratypes - a male, same data as holotype, (K. U.) ; a female, genitalia and abdominal sternites on slide, from Temascal, Oax., México, Jan. 27, 1964, reared from larva in thorn of Acacia cornigera infested by Pseudomyrmex ferruginea F. Smith (U. S. N. M.); a female, from $2 \mathrm{mi}$. W. of Coatepeque, Quetzaltenango, Guatemala, Jan. I2, I965, reared from larva in thorn of Acacia hindsii infested with Pseudomyrmex ferruginea, (K. U.).

This species differs from all Hyperaspis known to me in two, perhaps significant, characters. (I) The antennal club has the terminal ( I Ith) segment free and considerably longer than the tenth, which in turn is as long as the ninth. In other Hyperaspis, both those with ten-segmented or eleven-segmented antenna, the terminal segment is very small and more or less buried in the apex of the penultimate segment, which is much shorter than the antepenultimate segment. 
(2) 'The basal part of the receptaculum does not bear an apical appendix as in the other species of the genus known to me.

\section{IJiterature Cited}

DOBZHANSKY, T:

1941. Smithsonian Miscellaneous Collections, 106 (6): 1-94, 6 plates. KORSCHEFSKY, R.

1931. Coleop. Catalogus (Junk), pars 118: 176-209.

SchWARz, E. A.

1890. Proc. Ent. Soc. Washington, 1 (4) : 237-247. Silvestri, F.

1903. Ann. Mus. Zool. R. Univ. Napoli, N.S., 1 (13): 3.

SмITH, J. B.

1886. Amer. Nat., 20:679-687.

WHEELER, W. M.

1911. Journ. New York Ent. Soc., 19 (3): 169-174.

'THE AN'T APHAENOGASTER GATESI TRANSFERRED TO PHEIDOLE.-Pheidole gatesi is the necessary NEW COM BINATION for Aphaenogaster (Attomyrma) gatesi Wheeler, 1927. Psyche, 34: 44, worker (minor); type locality Rangoon, Burma. The types of $A$. gatesi are really minors of some species of the Pheidole smythiesi group (= subgenus Ceratopheidole). When compared directly with types of $P$. smythiesi, the gatesi cotypes showed differences in head shape and in details of the mesonotum and postpetiole that are strong enough to indicate distinctness at the species level, at least until we have further knowledge of intraspecific variation in this group. The type comparison was incidental to work done in European museums during 1963 under National Science Foundation Grant G-2368o. - W. L. Brown, Jr., Department of Entomology, Cornell University. 

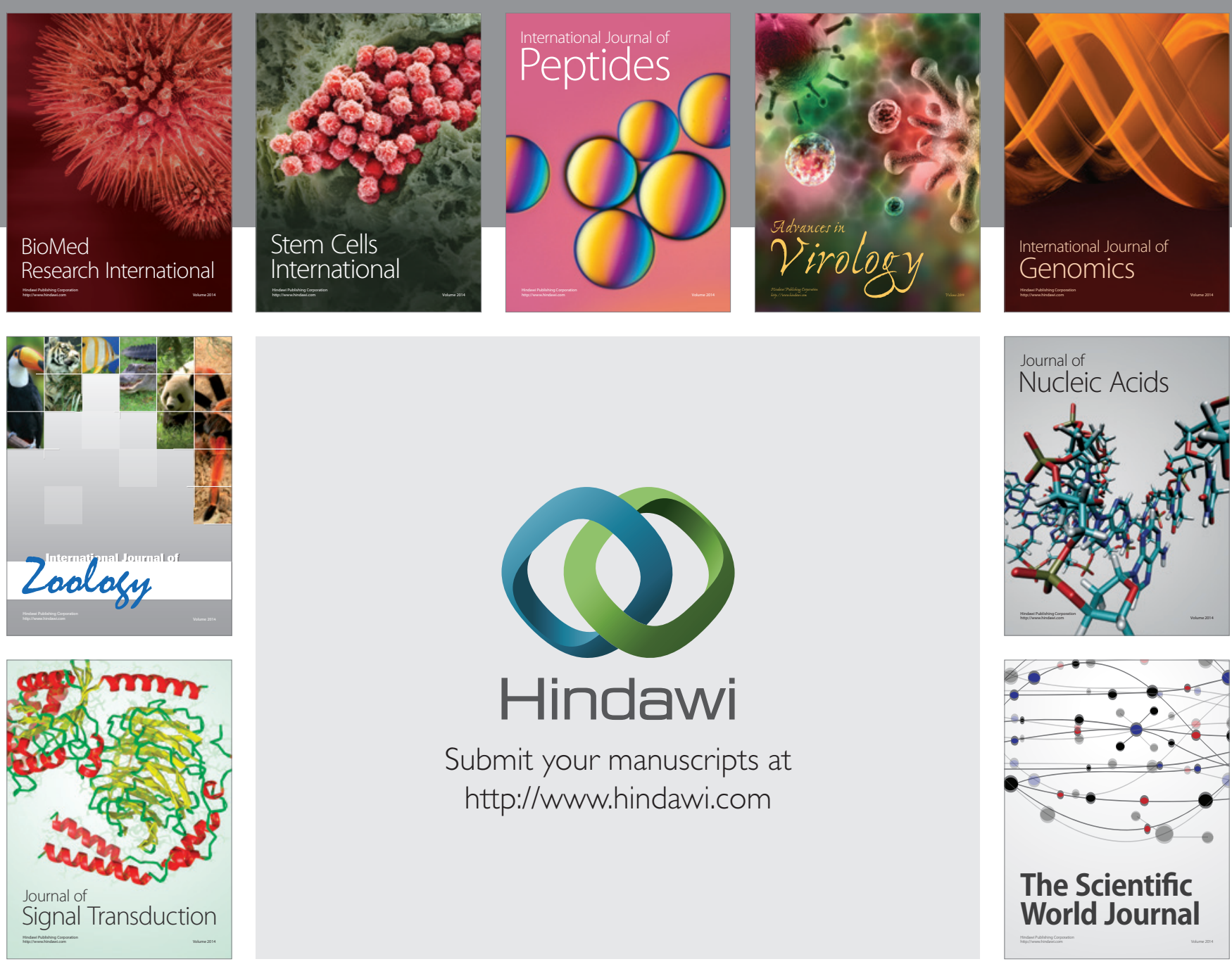

Submit your manuscripts at

http://www.hindawi.com
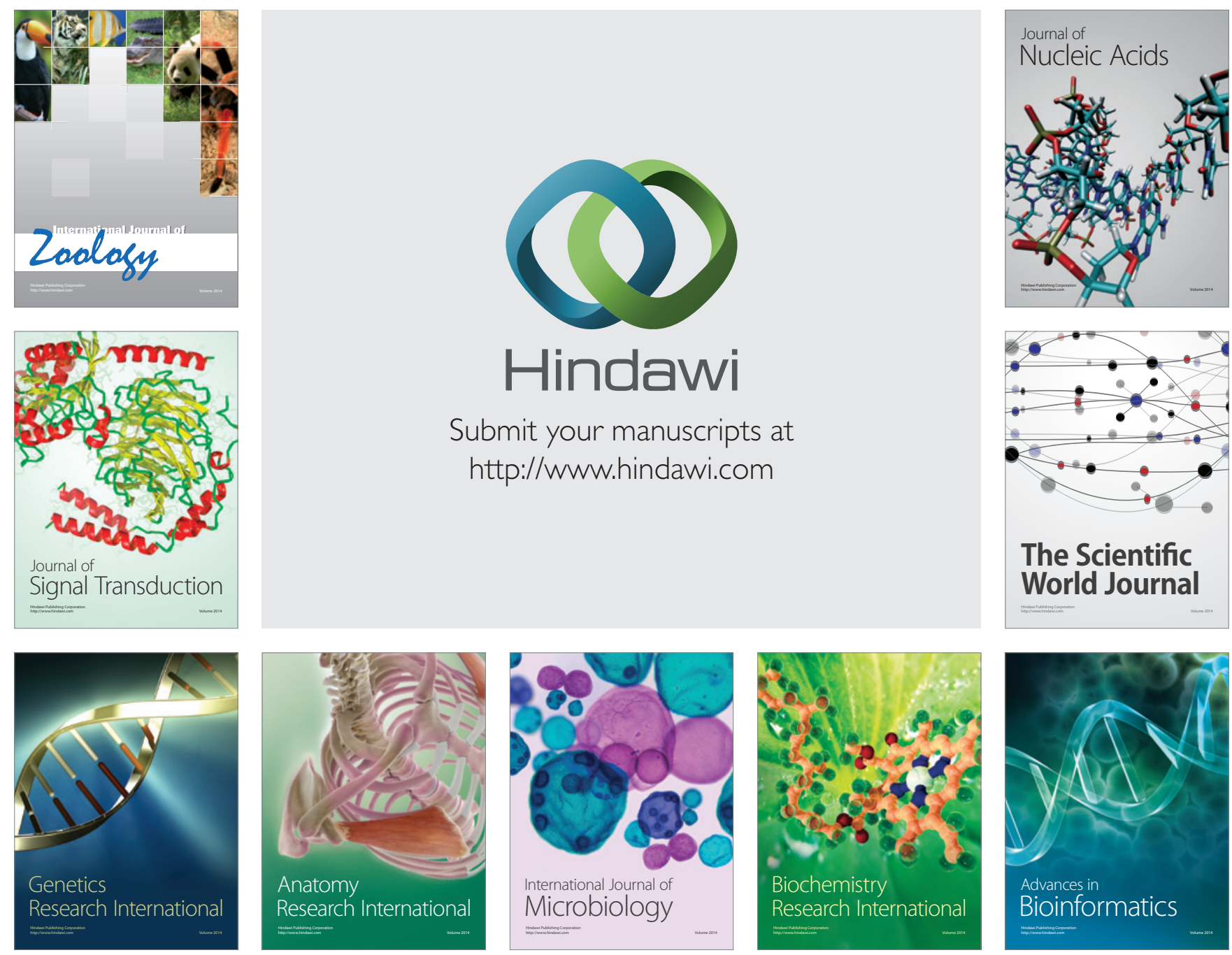

The Scientific World Journal
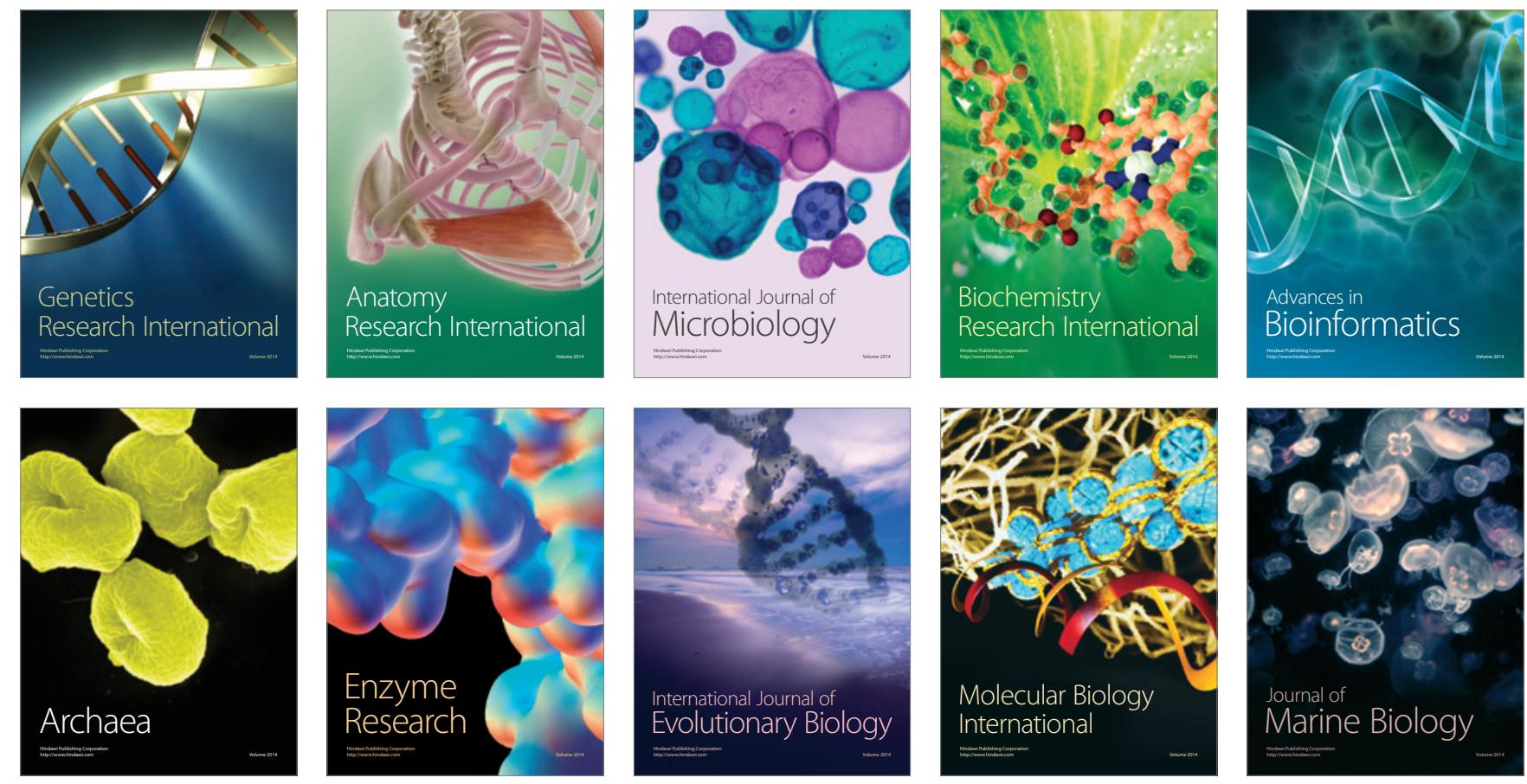